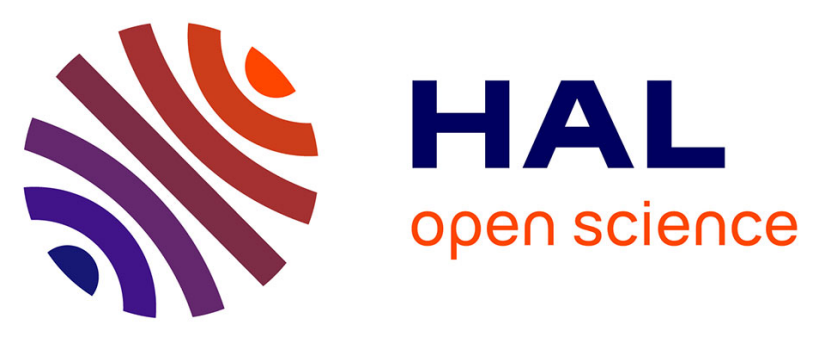

\title{
Towards the development of an autocontamination trap system to manage populations of emerald ash borer (Coleoptera: Buprestidae) with the native entomopathogenic fungus, Beauveria bassiana.
}

D Barry Lyons, Robert Iavallée, George Kyei-Poku, Kees van Frankenhuyzen, Shajahan Johny, Claude Guertin, Joseph A Francese, Gene C Jones, Martine Blais

\section{- To cite this version:}

D Barry Lyons, Robert Iavallée, George Kyei-Poku, Kees van Frankenhuyzen, Shajahan Johny, et al.. Towards the development of an autocontamination trap system to manage populations of emerald ash borer (Coleoptera: Buprestidae) with the native entomopathogenic fungus, Beauveria bassiana.. Journal of Economic Entomology, 2012, 105 (6), pp.1929-39. 10.1603/EC12325 . pasteur-01002315

\section{HAL Id: pasteur-01002315}

https://hal-riip.archives-ouvertes.fr/pasteur-01002315

Submitted on 5 Jun 2014

HAL is a multi-disciplinary open access archive for the deposit and dissemination of scientific research documents, whether they are published or not. The documents may come from teaching and research institutions in France or abroad, or from public or private research centers.
L'archive ouverte pluridisciplinaire HAL, est destinée au dépôt et à la diffusion de documents scientifiques de niveau recherche, publiés ou non, émanant des établissements d'enseignement et de recherche français ou étrangers, des laboratoires publics ou privés. 


\section{Towards the Development of an Autocontamination Trap System to Manage Populations of Emerald Ash Borer (Coleoptera: Buprestidae) with the Native Entomopathogenic Fungus, Beauveria bassiana}

Author(s): D. Barry Lyons, Robert Lavallée, George Kyei-Poku, Kees Van Frankenhuyzen, Shajahan Johny, Claude Guertin, Joseph A. Francese, Gene C. Jones, and Martine Blais

Source: Journal of Economic Entomology, 105(6):1929-1939. 2012.

Published By: Entomological Society of America

URL: http://www.bioone.org/doi/full/10.1603/EC12325

BioOne (www.bioone.org) is a nonprofit, online aggregation of core research in the biological, ecological, and environmental sciences. BioOne provides a sustainable online platform for over 170 journals and books published by nonprofit societies, associations, museums, institutions, and presses.

Your use of this PDF, the BioOne Web site, and all posted and associated content indicates your acceptance of BioOne's Terms of Use, available at www.bioone.org/page/terms of use.

Usage of BioOne content is strictly limited to personal, educational, and non-commercial use. Commercial inquiries or rights and permissions requests should be directed to the individual publisher as copyright holder. 


\title{
Towards the Development of an Autocontamination Trap System to Manage Populations of Emerald Ash Borer (Coleoptera: Buprestidae) With the Native Entomopathogenic Fungus, Beauveria bassiana
}

\author{
D. BARRY LYONS ${ }^{1,2}$ ROBERT LAVALLÉE, ${ }^{3}$ GEORGE KYEI-POKU, ${ }^{1}$ \\ KEES VAN FRANKENHUYZEN, ${ }^{1}$ SHAJAHAN JOHNY, ${ }^{1}$ CLAUDE GUERTIN, ${ }^{4}$ \\ JOSEPH A. FRANCESE, ${ }^{5}$ GENE C. JONES, ${ }^{1}$ AND MARTINE BLAIS ${ }^{3}$
}

J. Econ. Entomol. 105(6): 1929-1939 (2012); DOI: http://dx.doi.org/10.1603/EC12325

\begin{abstract}
Emerald ash borer, Agrilus planipennis Fairmaire (Coleoptera: Buprestidae) is an invasive species from Asia that was discovered in North America Canada, in 2002. Herein, we describe studies to develop an autocontamination trapping system to disseminate Beauveria bassiana to control beetle populations. The standard trap for emerald ash borer in Canada is a light green prism trap covered in an insect adhesive and baited with (Z)-3-hexenol. We compared of green multifunnel traps, green intercept panel traps (both with and without fluon coating) and green prism traps for capturing emerald ash borer in a green ash plantation. The coated green multifunnel traps captured significantly more males and more females than any other trap design. We examined the efficacy of two native $B$. bassiana isolates, INRS-CFL and L49-1AA. In a field experiment the INRS-CFL isolate attached to multifunnel traps in autocontamination chambers retained its pathogenicity to emerald ash borer adults for up to $43 \mathrm{~d}$ of outdoor exposure. Conidia germination of the INRS-CFL isolate was $>69 \%$ after outdoor exposure in the traps for up to $57 \mathrm{~d}$. The L49-1AA isolate was not pathogenic in simulated trap exposures and the germination rate was extremely low $(<5.3 \%)$. Mean $( \pm$ SEM $)$ conidia loads on ash borer adults after being autocontaminated in the laboratory using pouches that had been exposed in traps out of doors for $29 \mathrm{~d}$ were $579,200( \pm 86,181)$ and 2,400 ( \pm 681$)$ for the INRS-CFL and the L49-1AA isolates, respectively. We also examined the fungal dissemination process under field conditions using the L49-1AA isolate in a green ash plantation. Beetles were lured to baited green multifunnel traps with attached autocontamination chambers. Beetles acquired fungal conidia from cultures growing on pouches in the chambers and were recaptured on Pestick-coated traps. In total, 2,532 beetles were captured of which $165(6.5 \%)$ had fungal growth that resembled B. bassiana. Of these 25 beetles were positive for the L49-1AA isolate.
\end{abstract}

KEY WORDS Agrilus planipennis, entomopathogenic fungus, ash tree, autodissemination, invasive insect

The emerald ash borer, Agrilus planipennis Fairmaire (Coleoptera: Buprestidae), was detected for the first time in North America at Detroit, MI, and Windsor, ON, Canada, in 2002 (Haack et al. 2002), but dendrochronological evidence suggests that this beetle was present in those environs from the early 1990s (Cappaert et al. 2005). The beetle has killed tens of millions of its ash tree (Fraxinus spp.) hosts since its arrival from Asia and has been detected in 18 states of the United States and two Canadian provinces (EAB Info 2012).

\footnotetext{
${ }^{1}$ Natural Resources Canada, Canadian Forest Service, 1219 Queen Street East, Sault Ste. Marie, ON, P6A 2E5 Canada.

${ }^{2}$ Corresponding author, e-mail: barry.lyons@NRCan-RNCan. gc.ca.

${ }^{3}$ Natural Resources Canada, Canadian Forest Service, $1055 \mathrm{du}$ P.E.P.S., P.O. Box 10380, Sainte-Foy, QC, GlV 4C7 Canada.

${ }^{4}$ INRS-Institut Armand-Frappier, 531, des Prairies Boulevard, Laval, QC, H7V 1B7 Canada.

${ }^{5}$ USDA-APHIS PPQ, 1398 W. Truck Rd., Otis Air National Guard Base, Buzzards Bay, MA 02542.
}

Adults of emerald ash borer emerge in spring from their pupal chambers in the xylem or phloem of the host tree via characteristic D-shaped holes. In southwestern Ontario, Canada, emergence of adults begins in the last days of May, peaking in mid-June, while peak flight occurs in mid-July (Lyons and Jones 2005). Adults undergo a prolonged period of maturation feeding on host foliage before mating and oviposition (Cappaert et al. 2005). Median longevity of adults is 38 and $23 \mathrm{~d}$ in the laboratory at constant temperatures of 21 and $24^{\circ} \mathrm{C}$, respectively (Lyons and Jones 2005). Eggs are laid in bark crevices and under bark scales on the trunk or branches. Neonate larvae chew through the bottom of the egg and tunnel to the cambial layer where they feed on phloem and xylem tissues, destroying the vascular system of the host tree. Larvae pass through four larval instars finally overwintering as prepupae, although some individuals overwinter as earlier-instar larvae and undergo a 2-yr life cycle (Cappaert et al. 2005). 
Fungal entomopathogens may provide forest and urban tree managers with alternatives to the insecticides that are registered (Herms et al. 2009, Health Canada 2012) for control of emerald ash borer. Native fungal pathogens, including isolates of Beauveria bassiana (Balsamo) Vuillemin (Ascomycota: Hypocreales), have been reported at low prevalence $(<2 \%)$ in North American populations of emerald ash borer (Bauer et al. 2004). Indigenous strains of B. bassiana are as virulent to emerald ash borer as is the commercial GHA strain (Liu and Bauer 2006, Johny 2012) and may also have potential for managing emerald ash borer populations via spray applications (Castrillo et al. 2010a; Liu and Bauer 2008a,b). However, viability of B. bassiana conidia applied as bark or foliar sprays is rather short-lived (Castrillo et al. 2010a), and forest managers may be hesitant to use broad scale applications of generalist entomopathogens for fear of impacting nontarget insects.

The concept of autodissemination (Ignoffo 1978) is not new and there are several examples of using traps to autodisseminate fungal entomopathogens into pest populations (Furlong et al. 1995, Vega et al. 1995, Klein and Lacey 1999, Dowd and Vega 2003). The use of fungus impregnated nonwoven fiber bands (Hajek et al. 2006) resulted in $32 \%$ mortality of emerald ash borer adults (Liu and Bauer 2008a). The autodissemination approach requires live trapping of the pest species in large numbers, their contamination with fungal conidia, and subsequent escape so that conidia can be horizontally transferred to other members of the population.

There are currently no traps for live-trapping of emerald ash borer adults. In the United States, trapping for detection and delineation of emerald ash borer is done with purple prism traps (USDA-Animal and Plant Health Inspection Service [USDA-APHIS] 2011) that are coated with a sticky adhesive and baited with plant volatiles (Crook et al. 2008, Francese et al. 2010). Studies have demonstrated the strong visual attraction of emerald ash borer adults to green-colored traps (in the 525-560 $\mathrm{nm}$ range) (Crook et al. 2009, Francese et al. 2010), which work well in combination with the green leaf volatile, (Z)-3-hexenol (de Groot et al. 2008, Grant et al. 2010). Prism traps kill emerald ash borer adults by entrapping them in the sticky adhesive and are thus unsuitable as autocontamination traps. Czokajlo et al. (2003) described a black intercept panel trap that was effective in capturing forest Coleoptera including buprestids, while Francese et al. (2011) reported that green multifunnel traps caught as many or more emerald ash borer adults as purple prism traps. Those two trap types have shown promise for capturing emerald ash borer without the use of sticky adhesive and could be modified into autocontamination traps.

The objectives of our investigations were to: 1 ) compare the effectiveness of green intercept panel traps and green multifunnel traps as live traps for emerald ash borer adults; 2) test the effectiveness of an autocontamination chamber that provides a continuous source of fungal conidia by demonstrating that emerald ash borer adults can under laboratory conditions acquire a lethal dose from the autocontamination chamber; 3) ascertain that beetles can acquire the fungus from the autocontamination chamber under field conditions and disperse from the traps; 4) evaluate viability and pathogenicity of conidia produced in the autocontamination chamber throughout the flight period of emerald ash borer. The long-term goal of this study is to develop an autocontamination trapping system that can be used to manage new infestations of emerald ash borer.

\section{Materials and Methods}

Insect Rearing. Emerald ash borer adults used in the laboratory experiments were obtained from infested green ash (Fraxinus pennsylvanica Marshall) log bolts. Infested bolts were collected in December from a woodlot near Dutton, ON, Canada, and stored in the cold until spring. When beetles were needed, bolts were moved to $24^{\circ} \mathrm{C}$ and beetles were collected as they emerged. Beetles were kept in plastic rearing containers and provided with fresh ash foliage and water for up to $2 \mathrm{wk}$ before their use in pathogenicity tests.

For pathogenicity tests and beetle maintenance we used rearing containers consisting of two $350 \mathrm{ml}$ plastic tumblers placed mouth to mouth and taped together. The bottom of the upper plastic cup had been removed and replaced with aluminum mesh screening for ventilation. The stem of a partial compound ash leaf was inserted into a drilled hole in the cap of a 20-ml glass scintillation vial filled with water and placed in the lower cup to provide food for each adult. A vial, filled with tap water, with two dental wicks and a strip of synthetic shammy protruding through the opening provided water for each adult. The rearing containers were placed at $23 \pm 0.5^{\circ} \mathrm{C}$ relative humidity (RH) $60 \%$ and a photoperiod of 16:8 (L:D) h. Fresh foliage was provided as required throughout the course of the experiments and was collected from green ash trees in the Great Lakes Forestry Centre (GLFC) Arboretum in Sault Ste. Marie, ON, Canada.

Autocontamination Chamber. The design of the autocontamination chamber used in the traps will be described in a forthcoming manuscript by some of us (R.L., C.G., and M.B.) but an abbreviated description follows. The chamber consisted of two funnel sections from a green (530 nm; $57 \%$ reflectance) multifunnel trap (Synergy Semiochemicals, Burnaby, BC, Canada) attached spout to spout. The spout of a smaller clear plastic funnel (Nalgene $150 \mathrm{~mm}$; top internal diameter [i.d.] $15.0 \mathrm{~cm}$, spout i.d. $2.5 \mathrm{~cm}$, spout length $3.5 \mathrm{~cm}$ ) was inserted from the inside of one of the trap funnels out through the spout and into the spout of the second trap funnel and fixed in place with screws. A 50-ml polypropylene conical centrifuge tube (BD Falcon, BD Biosciences, San Jose, CA) cut at both ends was fixed to the stem of the small funnel to support the fungal pouch holder. Two rectangular layers of corrugated plastic measuring $\approx 9 \times 13 \mathrm{~cm}$ were used to hold the fungal pouches. A $28-\mathrm{mm}$ hole was drilled in the center of the rectangle to receive the conical tube. 
Four screws were mounted in the corners of the rectangle to secure the pouch. The pouch was pressed down onto the screws protruding though the plate that in turn protruded through the pouch. Plastic screw wall-anchors were used to affix the pouch to the screws. The conical tube was inserted through the hole in the plate such that a space was formed between the tube and the pouch to allow for the escape of beetles. Two bands of elastic strips were secured to the lower funnel by screws and secured the pouch in place.

Fungal Isolates and Culturing. Two isolates of $B$. bassiana were used in our experiments. The INRSCFL isolate of B. bassiana was originally isolated from Tomicus piniperda L. (Coleoptera: Curculionidae: Scolytinae) collected in a Scots pine plantation near Cookshire, QC, Canada, in 2002. The isolate was grown on Sabouraud Dextrose Agar (SDA) (Difco Laboratories, Germany) and was reactivated on Galleria mellonella L. (Lepidoptera: Pyralidae) to ensure the culture was not attenuated. This fungal isolate has been characterized using various molecular techniques (Sabbahi et al. 2009). The L49-1AA isolate of $B$. bassiana was collected from emerald ash borer cadavers from London, ON, Canada, and was described by Johny et al. (2012).

Fungus-inoculated substrates for use in the autocontamination chambers were produced as follows. The fungi were grown on solid medium of barley flakes. One hundred grams of barley flakes (La Meunerie Milanaise Inc., Milan, QC, Canada) were mixed with $50 \mathrm{ml}$ of distilled water and sterilized in a 1.5 mil polypropylene autoclavable bag $(25.4 \times 40.6$ $\mathrm{cm}$, Cole Parmer R-06501) for a 20 min liquid cycle at $121^{\circ} \mathrm{C}$. The cooled substrate was inoculated by transferring $2 \mathrm{ml}$ of liquid inoculum of B. bassiana $\left(10^{7}\right.$ $\mathrm{cfu} / \mathrm{ml}$ ) and $15 \mathrm{ml}$ of broth culture medium (without glucose; Bradley et al. 2002) directly into the substrate bag. The culture was allowed to grow for $7 \mathrm{~d}$ at $22^{\circ} \mathrm{C}$ under ambient $\mathrm{RH}$ and for another $7 \mathrm{~d}$ at $22^{\circ} \mathrm{C}$ under $90 \% \mathrm{RH}$ before putting it into the pouches. The $11 \times$ $14 \mathrm{~cm}$ pouches were fabricated from two layers of plastic screening (micromesh St-Gobain FCS7350) glued together along the edges to contain $\approx 75 \mathrm{ml}$ of inoculated barley flakes. The pouch was designed so that no fungal medium occurred in the center where rainfall would drain through the funnels. Pouches containing the inoculum were incubated for $5 \mathrm{~d}$ at $22^{\circ} \mathrm{C}$, $90 \% \mathrm{RH}$ so the surface of the screen was covered by a mat of conidia.

Comparison of Traps for Live Trapping. To develop an efficient autocontamination trap for emerald ash borer, we compared field captures of adults in green intercept panel traps and green multifunnel traps (see Francese et al. 2011) with the standard green prism trap, which is used for operational detection and delimitation of emerald ash borer populations in Canada (Grant et al. 2011, Natural Resources Canada [NRCan] 2012). Green intercept panel traps were constructed from the same light green corrugated plastic material ( $540 \mathrm{~nm}, 64.7 \%$ reflectance; Coroplast Inc., Dallas, TX) that is used in green prism traps, using a commercial Black Intercept Panel Trap (AlphaScents, Bridgeport, NY) as a template. Hardware and collecting cups, designed for use with the black intercept panel traps, were used with the green intercept panel traps, and were also purchased from AlphaScents. The green multifunnel traps consisted of 12 vertical funnels and were purchased from Synergy Semiochemicals Corp., as were the green prism traps. For each trap type, except the prism traps, we compared uncoated traps and traps that had been coated with Insect-a-Slip Barrier (BioQuip Products Inc., Rancho Dominguez, CA), a fluoropolymer ('fluon') resin (PTFE-30) suspension that makes smooth surfaces too slippery for insects to walk on. The fluon suspension was painted on the vertical panels of the green intercept panel traps as well as on the inside of the bottom funnel. For the multifunnel traps, the fluon suspension was painted on both inside and outside of each funnel. Fluon-treated surfaces were buffed with a cloth. All traps were baited with lures containing the green leaf volatile (Z)-3-hexenol (Synergy Semiochemicals Corp.). The green intercept panel traps and multifunnel traps were fitted with collecting cups that contained a saturated salt solution to kill and preserve the beetles.

The experimental site was an ash plantation/windbreak ( $42^{\circ} 53^{\prime} 28.90^{\prime \prime} \mathrm{N} 81^{\circ} 58^{\prime} 58.87^{\prime \prime} \mathrm{W}$ ) located in Lambton Co., ON, Canada. Traps were placed in the canopies of ash trees in two rows of 25 traps for a total of 50 traps in a complete random block design with 10 traps per treatment and $20 \mathrm{~m}$ between traps. The traps were suspended from branches at a height of $\approx 4-5 \mathrm{~m}$ above the ground using limb hangers (multifunnel, panel and prism traps) and spreaders (prism traps) (Midwest Wire Products LLC, Sturgeon Bay, WI) developed for the USDA-APHIS purple prism trap program (USDA-APHIS 2011). Traps were placed in the trees on 25 May 2011 and were sampled on 7 June, 13 June, 21 June, 28 June, 6 July, 13 July, 20 July, 26 July, and 9/10 August, when the traps were removed. Lures were replaced on 21 June. At each sample date, beetles were removed from the sticky prism traps or filtered from the saturated salt solution. The saturated salt solution was replenished in the collecting cups as required. All emerald ash borer adults were sexed by examination of the genitalia and counted.

Temporal Viability and Pathogenicity of Field-Exposed Fungal Isolates. Changes in viability and pathogenicity of conidia produced by the B. bassiana isolates in the autocontamination chambers over a timeframe spanning the period of emerald ash borer flight activity were investigated in a simulated field experiment. Ten multifunnel traps fitted with autocontamination chambers described above were hung on urban ash trees on the GLFC property on 30 June 2011. The traps were hung at $\approx 4-5 \mathrm{~m}$ above ground in the crown of the trees. Five pouches with the INRSCFL isolate and five with the L49-1AA isolate of $B$. bassiana were mounted individually in the autocontamination chambers of the 10 traps.

Viability of conidia was assessed by swiping each pouch on each collection date $(0,15,29,43$, and $57 \mathrm{~d}$ 
Table 1. The mean (SE) age and sex ratio (male/female) of adult emerald ash borer $(n=30)$ used in the pathogenicity bioassays of $B$. bassiana isolates in 2011

\begin{tabular}{|c|c|c|c|}
\hline \multirow{3}{*}{$\begin{array}{l}\text { Outdoor } \\
\text { exposure } \\
\text { period }(\mathrm{d})\end{array}$} & \multicolumn{3}{|c|}{ Mean (SE) age (d) and males/females } \\
\hline & \multirow{2}{*}{ Control } & \multicolumn{2}{|c|}{ Fungal isolate } \\
\hline & & INRS-CFL & L49-1AA \\
\hline 0 & $16.7(0.33) 15 / 15$ & $18.5(0.32) 14 / 16$ & $19.1(0.34) 15 / 15$ \\
\hline 15 & $12.6(0.46) 16 / 14$ & $14.5(0.46) 15 / 15$ & $12.1(0.35) 15 / 15$ \\
\hline 29 & $14.8(0.50) 16 / 14$ & $16.3(0.25) 15 / 15$ & $15.5(0.52) 15 / 15$ \\
\hline 43 & $10.5(0.49) 15 / 15$ & $9.5(0.54) 15 / 15$ & $5.6(0.73) 15 / 15$ \\
\hline
\end{tabular}

postoutdoor deployment) with sterile Q-tip swabs (Unilever, Clearwater, FL) and subsequently observing the germination rates. Three samples were collected from different areas of each pouch. The swabs were placed individually in $1.5 \mathrm{ml}$ microcentrifuge tubes and stored at $4^{\circ} \mathrm{C}$ until processed. At the time of processing, sterile $0.02 \%$ Tween 20 was added to each tube (500 $\mu$ l for the L49-1AA isolate and 1,000-1,500 $\mu \mathrm{l}$ for the INRS-CFL isolate because of the higher number of conidia). A 10- $\mu$ l aliquot was removed after vortexing to estimate the number of conidia using a hemocytometer (Hausser Scientific Co., Horsham, PA). A 100-300 $\mu \mathrm{l}$ aliquot (depending on the concentration of conidia) was then plated onto onefourth strength SDAY media (10 cm plate) to determine conidial viability. Plates were incubated at $23^{\circ} \mathrm{C}$ for 12-16 h after which $10 \mu \mathrm{l}$ of lactophenol cotton blue stain ( $0.5 \%$ cotton blue) was added, followed by examination of 100 conidia under $200 \times$ phase-contrast magnification. A conidium was considered to be viable if the germ tube was longer than the width of the conidium.

Temporal changes in pathogenicity of the fungal isolates during outdoor exposure were assessed by exposing beetles to each of the 10 fungal pouches on the day that the traps were deployed out of doors (day 0 ) and 15, 29, and $43 \mathrm{~d}$ after deployment. At each time interval, pouches were removed from the traps and placed sequentially in an autocontamination chamber in the laboratory. In total, six beetles was exposed to each pouch by dropping beetles one at a time into the upper funnel of the test chamber and collecting them upon exit. If the beetle did not exit from the pouch within $1 \mathrm{~min}$, it was prodded with sterile forceps. The beetles were placed individually in a rearing container with foliage and water, and were examined every $1-3$ $\mathrm{d}$ for mortality for $40 \mathrm{~d}$ posttreatment. Because of the logistic difficulties of synchronizing availability of emerged beetles with the exposure times, average age of the beetles varied among the various treatments (Table 1).

Conidia Load and Persistence on Emerald Ash Borer Adults. We ascertained the conidia load picked up by beetles during trap exit in the simulated field experiment on day 29 by exposing an additional five beetles (mixed sexes) per pouch as described above. Exited beetles were collected individually in $1.5 \mathrm{ml}$ microcentrifuge tubes and $500 \mu \mathrm{l}$ of $0.02 \%$ Tween 20 was added followed by agitation at $200 \mathrm{rpm}$ for $30 \mathrm{~min}$.
The samples were vortexed briefly before withdrawing an aliquot for haemocytometer counting.

To determine if $B$. bassiana can be recovered from contaminated adults after an outdoor exposure on sticky bands that corresponded to our sampling interval in the field trial ( $7 \mathrm{~d}$, see below), laboratorycontaminated beetles were placed on sticky-band traps on ash trees on the GLFC grounds. Seventy beetles were killed by freezing and were contaminated by rolling on a pouch containing an actively growing colony of the INRS-CFL isolate. Thirty-five contaminated beetles were placed on each of two traps on the same day (5 August 2011) around the circumference of the bole without regard to orientation. Five beetles were randomly removed from each trap at daily intervals up to $7 \mathrm{~d}$ after placement. The fungus was recovered, plated, and cultured as described below.

Autocontamination of Emerald Ash Borer Under Field Conditions. To demonstrate autocontamination of emerald ash borer adults under field conditions, 10 plots were set up in a green ash plantation $\left(42^{\circ}\right.$ $50^{\prime} 12.41^{\prime \prime} \mathrm{N} 81^{\circ} 57^{\prime} 53.53^{\prime \prime} \mathrm{W}$ ) in Lambton County, ON, Canada, in 2011. Trees had been planted in 1987-1988 with 2-m spacing between rows and 1.5-m spacing between trees within a row. Plots were spaced at least $25 \mathrm{~m}$ apart. Each plot consisted of a total of nine trees, three in each of three adjacent rows. A 12-funnel green multifunnel trap fitted with an autocontamination chamber was suspended in the mid-crown of the center tree in each plot. A pouch containing the L491AA isolate of B. bassiana was installed in the autocontamination chamber, and the trap was baited with (Z)-3-hexenol. Sticky band traps, to recapture autocontaminated beetles, were installed with their lower edge at breast height on the boles of the remaining eight outside trees. Each sticky band was formed by covering three overlapping layers of $50-\mathrm{cm}$ wide stretch-wrap (Staples Business Depot, Markham, ON) wrapped around the tree bole with Pestick (Phytotronics, Inc., Earth City, MO). An unbaited green prism trap was placed in the canopy of the middle southernmost tree in each plot.

All traps were installed on 24 May and beetles were collected from the sticky band traps and the green prism traps on 7 June, 14 June, 21 June, 28 June, 5 July, 12 July, 19 July, 26 July, and 9 July when the traps were removed. The $(\mathrm{Z})$-3-hexenol lures on the multifunnel traps were replaced on 21 June. On each sample date trapped beetles were placed individually in $1.5 \mathrm{ml}$ microcentrifuge tubes. The forceps were cleaned by first dipping in bleach (5.25\% sodium hypoclorite), then spraying with $70 \%$ ethanol and wiping with a new Kimwipe tissue after handling each individual beetle. All centrifuge tubes from the same plot were sealed within a Ziploc bag and placed at $4^{\circ} \mathrm{C}$ to be transported to the laboratory for assessment of fungal autocontamination.

To recover fungal isolates from the trapped beetles, each adult was washed by vortexing in $500 \mu \mathrm{l}$ of $0.02 \%$ Tween 20 and sterilized in bleach (5.25\% sodium hypoclorite) for $\approx 15 \mathrm{~s}$, followed by two rinses with 
autoclaved water. After drying on a Kimwipe tissue each beetle was placed on PDA medium (without antibiotics) in a petri dish that was sealed with Parafilm. All culturing was performed in a laminar-flow chamber using sterile techniques. The plates were then incubated at $25 \pm 1^{\circ} \mathrm{C}$ and $80 \% \mathrm{RH}$ and were examined for the presence of B. bassiana after $15 \mathrm{~d}$. Fungal cultures resembling $B$. bassiana were tested using DNA markers that are specific to the L49-1AA isolate. On each sample date, conidial viability was assessed as described above. Each pouch was swabbed three times, and germination rates were determined as before.

Statistical Analysis. All statistical analyses were conducted using Systat (Systat Software, Inc. 2008). Total numbers of males or females captured in each trap in the trap comparison experiments were transformed to logarithms $\left(\log _{10}(\right.$ adults +1$\left.)\right)$ to normalize the data and equalize the variance before one way analysis of variance (ANOVA) within sex. The Student-Newman-Keuls Method was then used for all pairwise multiple comparisons. If after the transformation either the Normality Test or the Equal Variance Test failed then the nonparametric Kruskal-Wallis ANOVA on Ranks was performed on the untransformed data followed by the Student-Newman-Keuls Method for all pairwise multiple comparisons.

To analyze the pathogenicity data, the number of beetles dying during each observation interval were subjected to Kaplan-Meier Survival Analysis using the Gehan-Breslow Test. The Holm-Sidak method was used for the all pairwise multiple comparisons. Insects that died from some obvious cause other than the effects of the pathogen (e.g., drowning in water vial or crushed) as well as those that were still alive at the end of the experiment ( $40 \mathrm{~d}$ ) were coded as censored data. The proportions ( $p$ ) of conidia of the INRS-CFL or L49-1AA isolates of $B$. bassiana that germinated at each outdoor exposure interval in Sault Ste. Marie and at the autocontamination release site in Lambton Co. were arcsine-square root transformed (i.e., $y=$ arcsine $(\operatorname{sqrt}(\mathrm{p})))$ to normalize the data and stabilize the variance, followed by one way ANOVA of germination rates at each time interval and pairwise multiple comparisons (Student-Newman-Keuls Method). If after transformation, the data failed either the Normality or the Equal Variance tests the untransformed data were analyzed using a Kruskal-Wallis one way ANOVA on Ranks followed by an all pairwise multiple comparison using Dunn's Method. The median conidia loads on adults of emerald ash borer, after exposure to the INRS-CFL and L49-1AA isolates were compared using the Mann-Whitney Rank Sum Test.

\section{Results}

Trap Comparisons. Trap treatment significantly influenced trap catch for both males $(F=20.611$; $\mathrm{df}=$ 4; $P<0.001)$ and females $(F=30.012$; df $=4 ; P<$ $0.001)$. The number of males and females captured were normalized by logarithmic transformation $(P=$ $0.086, P=0.521$, respectively) that equalized the vari-

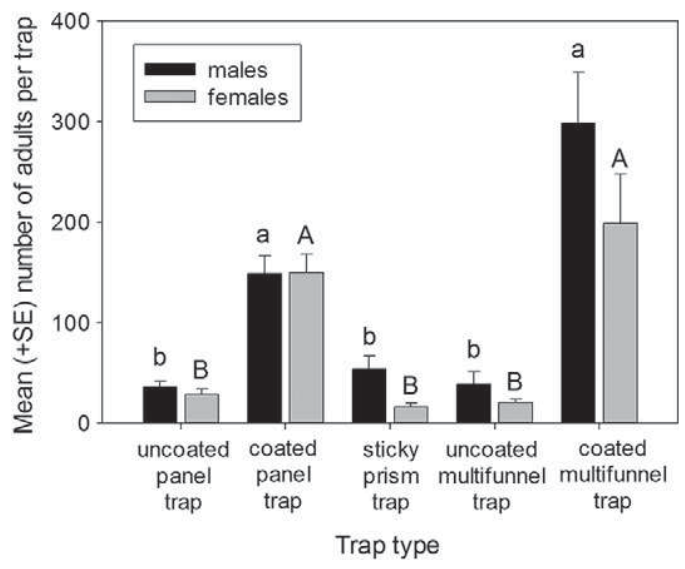

Fig. 1. Mean (+SE) trap captures of emerald ash borer adults from: 1) green intercept panel traps without fluon coating; 2) green intercept panel traps with fluon coating; 3) green sticky prism trap; 4) green multifunnel traps without fluon coating; 5) green multifunnel traps coated with fluon in Lambton Co., ON, Canada, in 2011. Different lower or upper case letters over bars indicate significant differences between treatments for males or females, respectively.

ance $(P=0.218, P=0.573$, respectively). For both males and females, trap catches with the fluon-coated green panel traps and the fluon-coated green multifunnel traps were significantly higher than with the uncoated green intercept panel trap, the green sticky prism trap and the uncoated green multifunnel trap, all three of which were not significantly different than each other (Fig. 1).

Fungal Pathogenicity to Emerald Ash Borer Adults. Most beetles treated in the laboratory with INRS-CFL and L49-1AA after outdoor exposure of the fungal pouches for $0,15,29$, and $43 \mathrm{~d}$ in the simulated experiment died within 6-12 d after contamination (Fig. 2 ). Mean survival times for treated beetles and untreated controls are listed in Table 2. Survival curves differed significantly within each exposure treatment $(P<0.001)$ (Table 2$)$. In each exposure period, mean survival times were consistently shorter for INRS-CFL treated beetles than for control beetles. Survival of beetles treated with L49-1AA was not significantly different from the untreated controls in all but one outdoor exposure period ( $29 \mathrm{~d}$ ). The mean survival time for the L49-1AA exposed group and the unexposed control group never differed by $>4.5 \mathrm{~d}$. Median survival times for INRS-CFL treated beetles ranged from 6 to $8 \mathrm{~d}$ for the four exposure periods. In the first two exposure periods ( 0 and $15 \mathrm{~d}$ ), mortality of the INRS-CFL exposed group reached $100 \%$ within the 40-d duration of the experiment (Fig. 2), whereas it remained below $100 \%$ in the last two outdoor exposure periods ( 29 and $43 \mathrm{~d}$ ).

Conidia Germination Rate After Outdoor Exposure of Fungal Pouches. The mean germination rate of conidia of the INRS-CFL isolate for all sample intervals up to $57 \mathrm{~d}$ of outdoor exposure in autocontamination traps varied between $69.1-79.6 \%$ (Fig. 3). For the first four intervals from the 0 -d sample up to the 


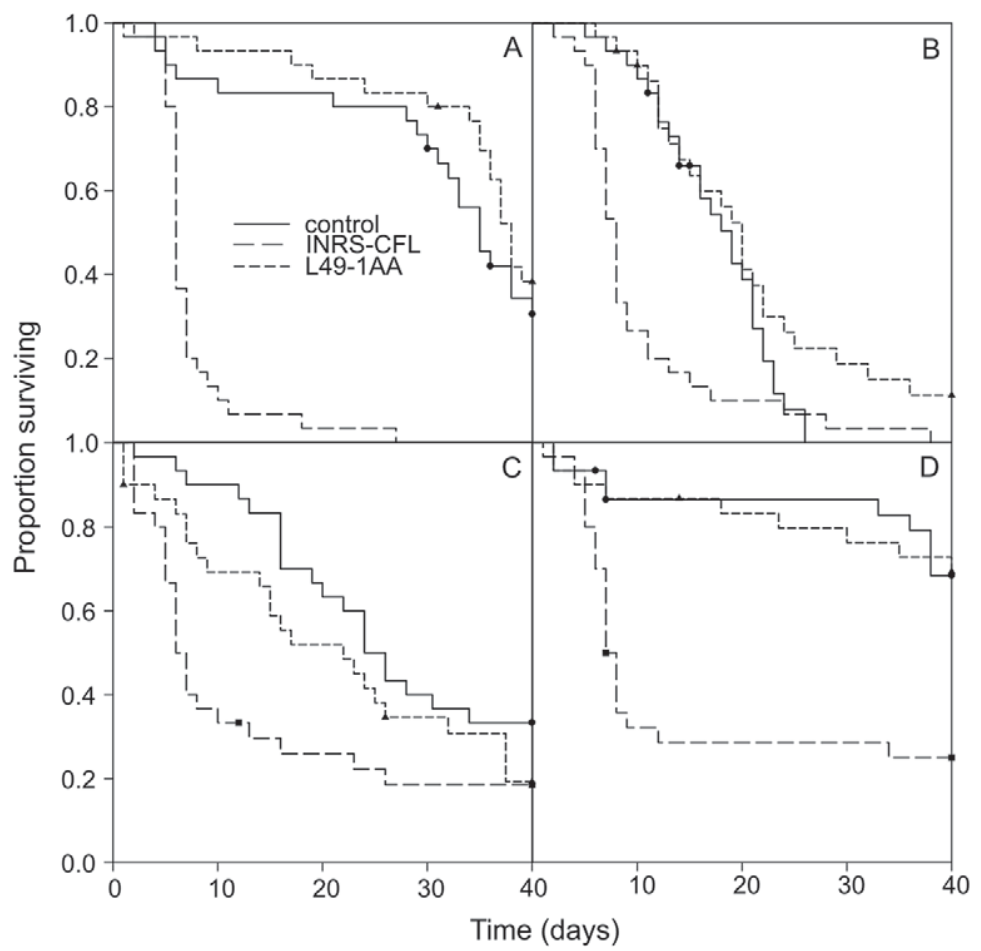

Fig. 2. Survival of emerald ash borer adults reared under laboratory conditions comparing beetles contaminated in the laboratory in a green autocontamination chamber with the CFL-INRS or L49-1AA isolates of B. bassiana, which had been exposed out of doors for (a) 0 , (b) 15, (c) 29, or (d) $43 \mathrm{~d}$ in an autocontamination chamber attached to a multifunnel trap in Sault Ste. Marie, ON, Canada, in 2011, and untreated controls. The symbols on the graphs represent the censored data.

43-d exposure the mean germination did not change significantly but there was a slight but significant drop in germination during the last interval (ANOVA: $F=$ 3.408 , df $=4, P=0.013$; normality: $P=279$; equal variance: $P=0.568)$. The mean germination rate for the L49-1AA isolate in the same test was considerably lower than for the INRS-CFL isolate (Fig. 3) and ranged from 0.8 to $5.3 \%$, with significant differences between sample intervals (Kruskal-Wallis one way ANOVA on Ranks: $H=17.030$, df $=4, P=0.002$; normality: $P<0.05)$. The last sample interval had a slightly higher germination rate compared with the initial germination rates at the early sample intervals.

Conidia Load on Emerald Ash Borer Adults After Outdoor Exposure of Fungal Isolates. Mean $( \pm \mathrm{SE}$ ) conidia loads on emerald ash borer adults after expo- sure in the laboratory to the INRS-CFL and L49-1AA isolates exposed outdoors in autocontamination chambers for $29 \mathrm{~d}$ were $579,200( \pm 86,181)$ and 2,400 ( \pm 681$)$ conidia per beetle, respectively. Thus, beetles exposed to the INRS-CFL isolate had significantly more conidia (Mann-Whitney U Statistic $=23.000 ; T=$ $348.000 ; P<0.001$ ) and 241 times more on average on their bodies than did the beetles exposed to the L491AA isolate.

Recovery of Contaminated Beetles in the Field After Autocontamination. In total, 2,532 emerald ash borer adults was captured on sticky band traps (323 males $+1,701$ females $=2,024$ beetles) and green prism traps ( 273 males +235 females $=508$ beetles $)$ in field plots with autocontamination traps. The cumulative percentages of beetles captured by the end

Table 2. Statistics for survival analysis of adults of emerald ash borer exposed to the INRS-CFL and L49-1AA isolates of B. bassiana that had been exposed outdoors in an autocontamination trap and an untreated control group

\begin{tabular}{|c|c|c|c|c|c|}
\hline \multirow{3}{*}{$\begin{array}{l}\text { Outdoor exposure } \\
\text { period }(d)\end{array}$} & \multicolumn{3}{|c|}{ Mean $(\mathrm{SE})$ survival time $(\mathrm{d})$} & \multirow{3}{*}{$\begin{array}{c}\text { Gehan-Breslow } \\
\text { statistic }\end{array}$} & \multirow{3}{*}{$P(\mathrm{df}=2)$} \\
\hline & \multirow{2}{*}{ Control } & \multicolumn{2}{|c|}{ Fungal isolate } & & \\
\hline & & INRS-CFL & L49-1AA & & \\
\hline 0 & $30.7(2.56) \mathrm{a}$ & $7.4(0.84) \mathrm{b}$ & $33.9(1.84) \mathrm{a}$ & 63.059 & $<0.001$ \\
\hline 15 & $17.4(1.07) \mathrm{a}$ & $10.1(1.39) \mathrm{b}$ & $20.8(1.90) \mathrm{a}$ & 38.734 & $<0.001$ \\
\hline 29 & $26.1(2.23) \mathrm{a}$ & $13.7(2.59) \mathrm{b}$ & $21.6(2.65) \mathrm{ab}$ & 14.726 & $<0.001$ \\
\hline 43 & $34.7(2.35) \mathrm{a}$ & $15.9(2.83) \mathrm{b}$ & $33.3(2.48) \mathrm{a}$ & 20.813 & $<0.001$ \\
\hline
\end{tabular}

Mean survival times followed by different letters from the same outdoor exposure period are from survival curves (Fig. 4) that are significantly different based on all pairwise multiple comparisons using the Holm-Sidak method (overall significance level $=0.05$ ). 


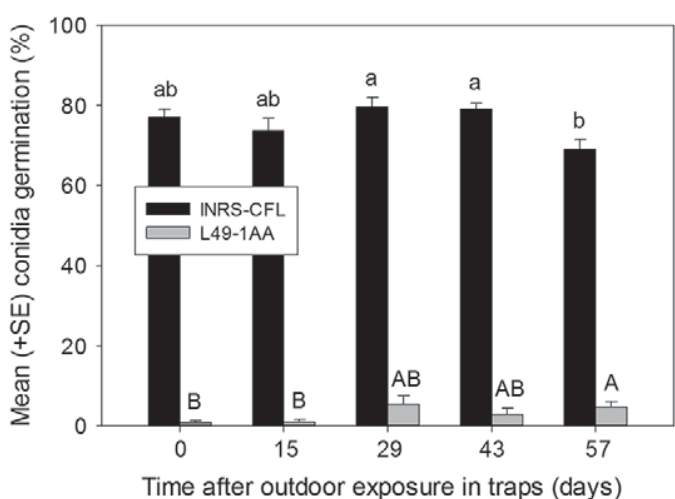

Fig. 3. Mean ( $+\mathrm{SE}$ ) conidia germination (\%) of the CFL-INRS and L49-1AA isolates of B. bassiana that had been exposed out of doors for $0,15,29,43$, and $57 \mathrm{~d}$ in an autocontamination chambers attached to a multifunnel trap in Sault Ste. Marie, ON, Canada, in 2011. Different lower or upper case letters over bars indicate significant differences between sample periods for the INRS-CFL and L49-1AA isolates, respectively.

of each sample period in days after deployment are shown in Fig. 4. No beetles were captured until 14-21 $\mathrm{d}$ after deployment indicating the beginning of the flight period. The flight period curve approached an asymptote by day 77 indicating the flight period was nearing its end. Of the beetles captured 165 (7.2\%) produced white powdery growth resembling $B$. bassiana after body washes were plated on PDA. Samples collected from these cultures and subjected to DNA probe analysis revealed that 25 beetles (1.0\%) were positive for the L49-1AA isolate of the fungus.

The mean germination rates for conidia of the L491AA isolate in the autocontamination traps are presented in Fig. 5. Arcsine-square-root transformation failed to normalize the data $(P<0.05)$ or equalize the variance $(P<0.05)$, thus a Kruskal-Wallis one way ANOVA on Ranks was used and indicated significant differences among medians $(H=147.650$; $\mathrm{df}=8 ; P<$ $0.001)$. Mean germination rates for the fungus were above $86 \%$ up to and including the 34-d postdeployment sample date, declined slightly and significantly below initial values to $77 \%$ by day 42 and remained at $>40 \%$ until day 77 .

A side experiment indicated that beetles on sticky traps retained fungal conidia throughout the 7-d sampling interval (Fig. 6). The percentage of beetles positive for $B$. bassiana throughout the $7 \mathrm{~d}$ of exposure was always $>67 \%$.

\section{Discussion}

One of our objectives was to demonstrate that we could collect large numbers of emerald ash borer adults in a nonsticky trap that is adaptable for autocontamination of adults with an entomopathogenic fungus. Purple and green prism traps that had been developed for area-wide detection and delimitation of emerald ash borer in the United States and Canada use

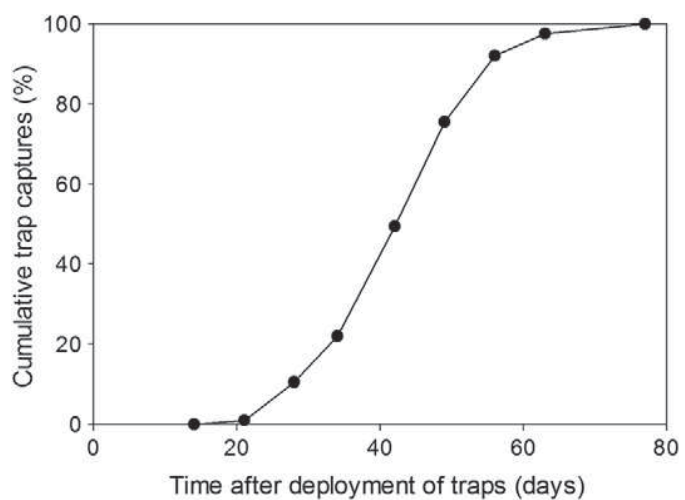

Fig. 4. Cumulative capture of adults of emerald ash borer in sticky band traps and unbaited green prism traps as a function of time after trap deployment (24 May 2011) in the autocontamination plots, Lambton, Co. ON, Canada, in 2011.

an insect adhesive to capture the beetles and thus are unsuitable for an autocontamination system. Beetles need to escape the traps with a dose of the fungus but remain alive for a sufficient amount of time to potentially cause horizontal or vertical transmission to other individuals in the population via mating, substrate contamination, or oviposition. Thus, green multifunnel traps provided us with a nonlethal trap for testing. Green uncoated panel traps, green uncoated multifunnel traps, and green prism traps all performed equally well in capturing males and females of emerald ash borer (Fig. 1). The autocontamination chambers that we used to autodisseminate fungal entomopathogen were designed to fit multifunnel traps and were fabricated from funnels for multifunnel traps.

The use of lubricants to enhance trap captures in intercept panel traps and multifunnel traps has been demonstrated previously (Sweeney et al. 2004, Graham et al. 2010, Allison et al. 2011, Graham and Poland 2012). By applying a slippery substance to the trap

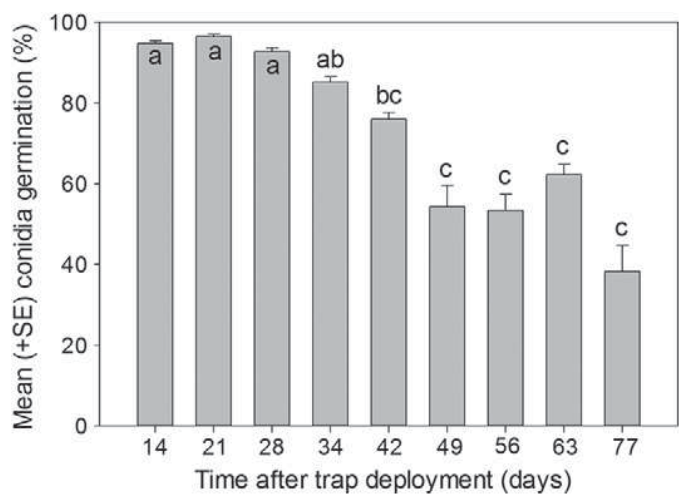

Fig. 5. Mean $(+\mathrm{SE})$ germination $(\%)$ of swabbed conidia from pouches containing the L49-1AA isolate of B. bassiana, as a function of time of exposure out of doors in autocontamination traps in Lambton, Co. ON, Canada, in 2011. Different lower case letters over bars indicate significant differences between sample periods. 


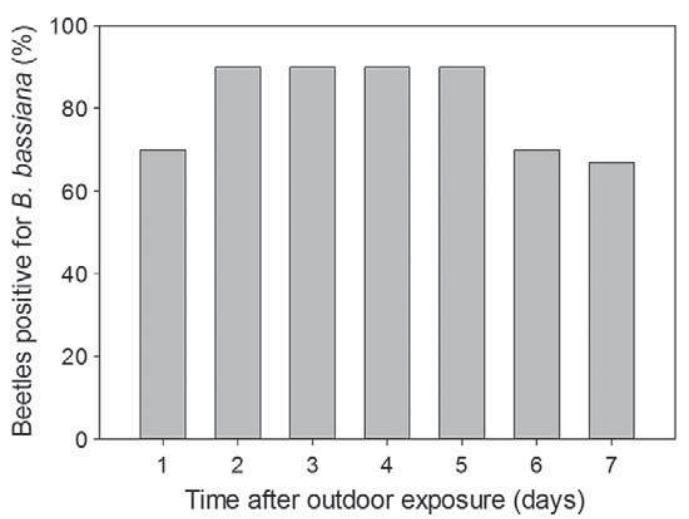

Fig. 6. Percentage of beetles positive for the INRS-CFL isolate of B. bassiana on laboratory-contaminated emerald ash borer adults $(n=10)$ after exposure for up to $7 \mathrm{~d}$ out of doors on two sticky band traps in Sault Ste. Marie, ON, Canada.

surface, insects are more likely to slide down into the collection receptacle. This seems to work particularly well for larger beetles like cerambycids and buprestids. The application of the windshield lubricant coating, Rain-X, when applied to purple multifunnel traps resulted in greater captures of emerald ash borer (Francese et al. 2011). The results obtained in our trap comparison studies showed that coating the green panel traps with fluon more than quadrupled the mean catch of males and more than quintupled the mean catch of females in comparison with the untreated green panel traps, while coating the multifunnel traps with fluon resulted in an almost eight-fold increase in mean male captures and an almost 10 -fold increase in female captures compared with the uncoated traps (Fig. 1). Mean captures of females in the coated green multifunnel traps were greater but not significantly different from captures in coated green intercept panel traps. However, mean captures of males in the same multifunnel traps were significantly greater and double the captures obtained by the comparable panel intercept traps. Thus, the coated green multifunnel trap outperformed all other treatments and satisfied the criteria for a trap that can capture large numbers of beetles and is compatible with the existing autocontamination chamber.

Like the attractant used in autocontamination traps for Japanese beetle (Klein and Lacey 1999), the attractant used in our traps, the green leaf volatile $(\mathbf{Z})$ 3-hexenol, has the advantage that it attracts both sexes to the autocontamination device, although males seem to be attracted preferentially (Grant et al. 2011). This might be an advantage to autodissemination of the fungus as males mate with multiple females (Rutledge and Keena 2012) via paratrooper copulation (Lelito et al. 2007) so that one infected male could potentially infect multiple females via horizontal transmission. Conidia may also disperse from infected cadavers. Horizontal transmission of fungal entomopathogens during mating has been reported in other wood-boring beetles (Kreutz et al. 2004, Peng et al. 2011).
Mating adults of emerald ash borer copulate for an average of $\approx 39 \mathrm{~min}$ (Wang et al. 2010), although no mate guarding occurs (Rutledge and Keena 2012) as it does in A. glabripennis (Peng et al. 2011), thus allowing substantial time for transfer of conidia between mates. However, horizontal and vertical transmission of fungal isolates in emerald ash borer populations remain to be demonstrated and require further investigation.

When the efficacy of pouches containing the INRSCFL isolate was determined after progressive periods of outdoor exposure in the simulated field experiment, the pathogenicity was evident for up to $43 \mathrm{~d}$ (Fig. 2). Pathogenicity declined after 29 and $43 \mathrm{~d}$ of outdoor exposure as shown by increased mean survival times (Table 2) and lack of complete mortality of the treated groups by $40 \mathrm{~d}$ posttreatment. However, this variability may have resulted from variation in mean age of test beetles or foliage quality over time.

The L49-1AA isolate failed to show significant pathogenicity for any of the outdoor exposure sample intervals (Fig. 1; Table 2). Earlier investigations (Johny et al. 2012) demonstrated that the fungus is pathogenic to emerald ash borer. Visual examination of the cultures in the pouches revealed low conidia production. This was confirmed by conidia counts on beetles exposed to pouches containing the INRS-CFL and the L49-1AA isolates that had been in traps for 29-d out of doors. Beetles exposed to the INRS-CFL isolate had 241 times more conidia than beetles exposed to the L49-1AA isolate. We suspect that the barley flake medium in the pouches was not optimum for conidia production by the L49-1AA isolate.

Viability of conidia after prolonged outdoor exposure in autocontamination traps was determined by the rates of conidia germination for the two isolates in the simulated field experiment. The mean percentage germination rate for the INRS-CFL isolate was $>74 \%$ for up to day 43 and declined slightly to $69 \%$ by day 57 (Fig. 3). The high longevity of the fungus in our system resulted from the fact that the conidia are produced continuously by an actively growing fungal culture and that the chamber protects the conidia from ultra violet (UV) light and rain. However, conidia germination of the L49-1AA isolate was poor, never exceeding $6 \%$, indicating that the few conidia produced were not viable. Johny et al. (2012) reported this isolated to be more virulent to emerald ash borer and produced more conidia on cadavers of emerald ash borer than did other indigenous isolates or the commercial GHA strain of B. bassiana. Poor germination in the simulated field experiment may be because of storage of the pouches in the cold during active sporulation before deployment in the autocontamination traps.

Adults of emerald ash borer are long lived and the emergence period is quite prolonged requiring the presence of fungal inoculum for a protracted period. Wei et al. (2007) reported mean adult longevities of 16.5 and $18.5 \mathrm{~d}$ for males and females, respectively, while Wang et al. (2010) reported a combined mean longevity for males and females of $20.6 \mathrm{~d}$. The eclosion 
period has been reported to last for $19 \mathrm{~d}$ (Wei et al. 2007). Our trap capture data reported herein indicated a flight period of $\approx 60 \mathrm{~d}$ when adults were active (Fig. 4), but the peak activity (53.5\% of beetles) lasted $\approx 2 \mathrm{wk}$. Liu and Bauer (2008b) made four separate applications of the GHA-strain of B. bassiana to cover the entire flight period of the beetle. Fungal inocula resulting from triple spray applications of the GHA strain of B. bassiana at biweekly intervals to ash boles and foliage in a commercial tree nursery declined significantly by $1 \mathrm{wk}$ after individual applications (Castrillo et al. 2010b), presumably as a result of exposure to UV and rainfall. Klein and Lacey (1999) indicated that conidia viability in Japanese beetle autocontamination traps dropped off by $50 \%$ after $6 \mathrm{~d}$ in their traps. Our data suggest that in our autocontamination traps, pouches only need to be deployed once during the season because the solid substrate maintains actively growing colonies that produce new conidia continuously.

A heavy dose of conidia from the INRS-CFL isolate was observed on the adults of A. planipennis that passed through the fungal contamination chambers in the laboratory and this might be an impediment to their dispersal capability. Estimates of mean conidia load of the INRS-CFL isolate on emerald ash borer adults after the pouches were exposed out of doors for $29 \mathrm{~d}$ was 579,200 conidia/beetle. Lacey et al. (1995) found a slightly significant reduction in arrival times at traps of Japanese beetles, Popillia japonica, that had been treated with conidia of the fungus Metarhizium anisopliae compared with untreated beetles in a markrelease-recapture experiment. The difference, however, may have been related to factors other than conidial load. The impact of conidial load on dispersal capability of A. planipennis needs to be quantified.

To assess the effectiveness of the autocontamination traps under field conditions, we deployed sticky band traps and green prism traps to recapture beetles that had potentially passed through the traps in a green ash plantation in southwestern Ontario. All captured beetles were screened for the released fungal isolate by culturing the beetles for the presence of $B$. bassiana and then using DNA markers to differentiate cultured isolates of the fungus. The low numbers of beetles ( 25 beetles $=1 \%$ of total captured beetles) contaminated with the L49-1AA isolate of the fungus is consistent with the observation of low conidia production by this isolate on the barley pouches. Despite this low number, we have demonstrated that a fungal isolate can be autodisseminated using our trap system into emerald ash borer habitat. Future research is necessary to examine this release protocol with the better growing and conidia producing INRS-CFL isolate of $B$. bassiana and to develop a better growth medium to enhance conidia production by the L491AA isolate in the pouches.

We also examined the germination rate of the conidia at each sample interval up to $77 \mathrm{~d}$ after deployment of the traps in the ash plantation. Even though the conidia production by the L49-1AA isolate was low based on visual observation, conidia germi- nation was considerably better than the exposure of this isolate in the Sault Ste. Marie trial and stayed relatively high $(>80 \%)$ for the first $34 \mathrm{~d}$ in the field and dropped off gradually thereafter to a minimum of $\approx 40 \%$ after $77 \mathrm{~d}$ (Fig. 5). These data are consistent with the persistence of viability of INRS-CFL conidia in the simulated field experiment (Fig. 3), and confirm that in our trap system the same fungal culture can be deployed for the duration of the flight season. We attribute the difference in conidial viability of L49A between the simulated field trial in SSM and the actual field trial to the fact that pouches used in the simulated field trial were stored in the cold while in the conidial production stage.

The sample interval for our sticky band and green prism traps was weekly. Concern for the viability of fungal conidia on beetles that had passed through the autocontamination traps and had been recaptured on sticky band or green prism traps, prompted us to examine the viability of conidia on sticky bands. More than $66 \%$ of the beetles remained positive for B. bassiana on each of the $7 \mathrm{~d}$ after placement on the sticky bands indicating little degradation of the fungus for at least $7 \mathrm{~d}$ postcontamination.

Entomopathogenic fungi tend to be generalists and affect insects from a diverse array of insect taxa. Forest managers may be reluctant to use foliar and trunk applications of entomopathogenic fungi like B. bassiana for control of emerald ash borer for fear of impacting nontarget insect species. The impact of a fungal entomopathogen on hymenopterous parasitoids has been demonstrated (Furlong and Pell 2000). Although Dean et al. (2012) have shown in the laboratory that the two larval parasitoids of emerald ash borer from China that have been released in North America as classical biocontrol agents are relatively immune to standard doses of B. bassiana, the impact of the fungus on other elements of the environment including native parasitoids is unknown. The use of autocontamination traps to disperse the fungus via traps that preferentially attract the target species may mitigate nontarget impacts. Parasitoids might also be able to disseminate entomopathogens (Ignoffo 1978), but must be less susceptible to the pathogen than the target insect host. The role of abundant native parasitoids, like Phasgonophora sulcata Westwood, Atanycolus cappaerti Marsh, and Strazanac, and A. hicoriae Shenefelt (Lyons 2010), in this process needs to be evaluated.

Herein, we have demonstrated that A. planipennis will respond in large numbers to panel traps and multifunnel traps in the field that can be readily converted to live traps and fitted with a fungal autocontamination chambers. In the laboratory we have demonstrated that beetles can readily pick up a lethal dose of conidia when they pass through the autocontamination chambers and in the field we have shown that beetles can acquire the pathogen from the traps and disperse from the traps. We anticipate that this work will contribute to the development of potential emerald ash borer approaches involving autodissemination of indigenous fungal pathogens. 


\section{Acknowledgments}

We thank M. Campbell, C. Dietrich, D. Gauthier, Y. Liu, L. Roscoe, T. Shewchenko, and A. Tonon (NRCan-CFS, Sault Ste. Marie, ON) for technical assistance in the laboratory and field. We are grateful to P. DeMoor, J. Griffith, C. Kennedy, and D. Allen for allowing us access to the ash plantations on their properties. The project was funded by the Forest Invasive Alien Species Program from Natural Resources Canada, Canadian Forest Service, the Invasive Species Research Partnership Fund from the Ontario Ministry of Natural Resources, and the SERG-I research consortium. Green multifunnel traps were supplied by the USDA-APHIS-PPQ, Buzzards Bay, MA.

\section{References Cited}

Allison, J. D., C. W. Johnson, J. R. Meeker, B. L. Strom, and S.M. Butler. 2011. Effect of aerosol surface lubricants on the abundance and richness of selected forest insects captured in multiple-funnel and panel traps. J. Econ. Entomol. 104: 1258-1264.

Bauer, L. S., H. Liu, R. A. Haack, T. R. Petrice, and D. L. Miller. 2004. Natural enemies of emerald ash borer in southeastern Michigan, pp. 33-34. In V. Mastro and R. Reardon (comps.), Emerald Ash Borer Research and Technology Development Meeting, 30 September-1 October 2003. Port Huron, MI. FHTET-2004-02. U.S. Dep. Agric. Forest Service, Morgantown, WV.

Bradley, C. A., P. P. Wood, W. E. Black, R. D. Kearns, and J. Britton, inventors. 2002. Solid culture substrate including barley. U.S. patent application number 2002/0006650. (http://www.freepatentsonline.com/20020006650.pdf).

Cappaert, D., D. G. McCullough, T. M. Poland, and N. W. Siegert. 2005. Emerald ash borer in North America: a research and regulatory challenge. Am. Entomol. 51: 152165.

Castrillo, L. A., L. S. Bauer, H. Liu, M. H. Griggs, and J. D. Vandenberg. 2010a. Characterization of Beauveria bassiana (Ascomycota: Hypocreales) isolates associated with Agrilus planipennis (Coleoptera: Buprestidae) populations in Michigan. Biol. Control 54: 135-140.

Castrillo, L. A., M. H. Griggs, H. Liu, L. S. Bauer, and J. D. Vandenburg. 2010b. Assessing deposition and persistence of Beauveria bassiana GHA (Ascomycota: Hypocreales) applied for control of the emerald ash borer, Agrilus planipennis (Coleoptera: Buprestidae), in a commercial tree nursery. Biol. Control 54: 61-67.

Crook, D. J., J. A. Francese, K. E. Zylstra, I. Fraser, A. J. Sawyer, D. W. Bartels, D. R. Lance, and V. C. Mastro. 2009. Laboratory and field response of the emerald ash borer (Coleoptera: Buprestidae), to selected regions of the electromagnetic spectrum. J. Econ. Entomol. 102: $2160-2169$.

Crook, D. J., A. Khrimian, J. A. Francese, I. Fraser, T. M. Poland, A. J. Sawyer, and V. C. Mastro. 2008. Development of a host-based semiochemical lure for trapping emerald ash borer, Agrilus planipennis (Coleoptera: Buprestidae). Environ. Entomol. 37: 356-365.

Czokajlo, D., J. McLaughlin, L. I. Abu Ayyash, S. Teale, J. Wickham, J. Warren, R. J. Hoffman, B. Aukema, K. Raffa, and P. Kirsch. 2003. Intercept Panel Trap (INT PT) effective in management of forest Coleoptera, pp. 125-126. In M. L. McManus and A. M. Liebhold (eds.), Proceedings: Ecology, Survey and Management of Forest Insects, 1-5 September 2002, Krakow, Poland. General Technical Report NE-311. U.S. Dep. Agric. Forest Service, Newton Square, PA. de Groot, P., G. G. Grant, T. M. Poland, R. Scharbach, L. Buchan, R. W. Nott, L. MacDonald, and D. Pitt. 2008. Electrophysiological response and attraction of emerald ash borer to green leaf volatiles (GLVs) emitted by host foliage. J. Chem. Ecol. 34: 1170-1179.

Dean, K. M., J. D. Vandenberg, M. H. Griggs, L. S. Bauer, and M. K. Fierke. 2012. Susceptibility of two hymenopteran parasitoids of Agrilus planipennis (Coleoptera: Buprestidae) to the entomopathogenic fungus Beauveria bassiana (Ascomycota: Hypocreales). J. Invertebr. Pathol. 109: 303-306.

Dowd, P. F., and F. E. Vega. 2003. Autodissemination of Beauveria bassiana by sap beetles (Coleoptera: Nitidulidae) to overwintering sites. Biocontrol Sci. Tech. 13: $65-75$.

EAB Inf. 2012. Emerald ash borer information. (http:// www.emeraldashborer.info/ ).

Francese, J. A., D. J. Crook, I. Fraser, D. R. Lance, A. J. Sawyer, and V. C. Mastro. 2010. Optimization of trap color for the emerald ash borer, Agrilus planipennis (Coleoptera: Buprestidae). J. Econ. Entomol. 103: 1235-1241.

Francese, J. A., I. Fraser, D. Lance, and V. C. Mastro. 2011. Efficacy of multifunnel traps for capturing emerald ash borer (Coleoptera: Buprestidae): effect of color, glue, and other trap coatings. J. Econ. Entomol. 104: 901-908.

Furlong, M. J., and J. K. Pell. 2000. Conflicts between a fungal entomopathogen, Zoophthora radicans, and two larval parasitoids of the diamondback moth. J. Invertebr. Pathol. 76: 85-94.

Furlong, M. J., J. K. Pell, P. C. Ong, and A. R. Syed. 1995. Field and laboratory evaluation of a sex pheromone trap for the autodissemination of the fungal entomopathogen Zoophthora radicans (Entomophthorales) by the diamondback moth, Plutella xylostella (Lepidoptera: Yponomeutidae). Bull. Entomol. Res. 85: 331-337.

Graham, E. E., R. F. Mitchell, P. F. Reagel, J. D. Barbour, J. G. Millar, and L. M. Hanks. 2010. Treating panel traps with a fluoropolymer enhances their efficiency in capturing cerambycid beetles. J. Econ. Entomol. 103: 641-647.

Graham, E. E., and T. M. Poland. 2012. Efficacy of fluon conditioning for capturing cerambycid beetles in different trap designs and persistence on panel traps over time. J. Econ. Entomol. 105: 395-401.

Grant, G. G., T. M. Poland, T. Ciaramitaro, D. B. Lyons, and G. C. Jones. 2011. Comparison of male and female emerald ash borer (Coleoptera: Buprestidae) responses to phoebe oil and (Z)-3-hexenol lures in light green prism traps. J. Econ. Entomol. 104: 173-179.

Grant, G. G., K. L. Ryall, D. B. Lyons, and M. M. Abou-Zaid. 2010. Differential response of male and female emerald ash borers (Col., Buprestidae) to (Z)-3-hexenol and manuka oil. J. Appl. Entomol. 134: 26-33.

Haack, R. A., E. Jendek, H. Liu, K. R. Marchant, T. R. Petrice, T. M. Poland, and H. Ye. 2002. The emerald ash borer: a new exotic pest in North America. Newsl. Mich. Entomol. Soc. 47: 1-5.

Hajek, A. E., B. Huang, T. Dubois, M. T. Smith, and Z. Li. 2006. Field studies of control of Anoplophora glabripennis (Coleoptera: Cerambycidae) using fiber bands containing the entomopathogenic fungi Metarhizium anisopliae and Beauveria bringniartii. Biocontrol Sci. Tech. 16: 329343.

Health Canada. 2012. Pesticides and pest management. (http://www.hc-sc.gc.ca/cps-spc/pest/index-eng.php).

Herms, D. A., D. G. McCullough, D. R. Smitley, C. Sadof, R. C. Williamson, and P. L. Nixon. 2009. Insecticide options for protecting ash trees from emerald ash borer. 
North Central IPM Center Bulletin. (http:/ /www.ncipmc. org/resources/EAB\%20Bulletin\%20June.pdf).

Ignoffo, C. M. 1978. Strategies to increase the use of entomopathogens. J. Invertebr. Pathol. 31: 1-3.

Johny, S., G. Kyei-Poku, D. Gauthier, K. van Frankenhuyzen, and P. J. Krell. 2012. Characterization and virulence of Beauveria spp. recovered from emerald ash borer in southwestern Ontario, Canada. J. Invertebr. Pathol. 111: 41- 49 .

Klein, M. G., and L. A. Lacey. 1999. An attractant trap for autodissemination of entomopathogenic fungi into populations of the Japanese beetle Popillia japonica (Coleoptera: Scarabaeidae). Biocontrol Sci. Tech. 9: 151-158.

Kreutz, J., G. Zimmermann, and O. Vaupel. 2004. Horizontal transmission of the entomopathogenic fungus Beauveria bassiana among the spruce bark beetle, Ips typographicus (Col., Scolytidae) in the laboratory and under field conditions. Biocontrol Sci. Tech. 14: 837-848.

Lacey, L. A., J. J. Amaral, J. Coupland, M. G. Klein, and A. M. Simoes. 1995. Flight activity of Popillia japonica (Coleoptera: Scarabaeidae) after treatment with Metarhizium anisopliae. Biol. Control 5: 167-172.

Lelito, J. P., I. Fraser, V. C. Mastro, J. H. Tumlinson, K. Boroczky, and T. C. Baker. 2007. Visually mediated 'paratrooper copulations' in the mating behaviour of Agrilus planipennis (Coleoptera: Buprestidae), a highly destructive invasive pest of North American ash trees. J. Insect Behav. 20: 537-552.

Liu, H., and L. S. Bauer. 2006. Susceptibility of Agrilus planipennis (Coleoptera: Buprestidae) to Beauveria bassiana and Metarhizium anisopliae. J. Econ. Entomol. 99: 10961103.

Liu, H., and L. S. Bauer. 2008a. Microbial control of emerald ash borer, Agrilus planipennis (Coleoptera: Buprestidae) with Beauveria bassiana strain GHA: greenhouse and field trials. Biol. Control 45: 124-132.

Liu, H., and L. S. Bauer. 2008b. Microbial control of emerald ash borer, Agrilus planipennis (Coleoptera: Buprestidae) with Beauveria bassiana strain GHA: field applications. Biocontrol Sci. Tech. 18: 124-132.

Lyons, D. B. 2010. Biological control of emerald ash borer, pp. 29-34. In D. B. Lyons and T. A. Scarr (eds.), Workshop Proceedings: Guiding Principles for Managing the Emerald Ash Borer in Urban Environments, 18 November 2009, Burlington, ON. Natural Resources Canada and Ontario Ministry of Natural Resources, Sault Ste. Marie, $\mathrm{ON}$.

Lyons, D. B., and G. C. Jones. 2005. The biology and phenology of the emerald ash borer, pp. 62-63. In K. W.
Gottschalk (ed.), Proceedings 16th U.S. Department of Agriculture Interagency Research Forum on Gypsy Moth and Other Invasive Species, 2005, 18-21 January 2005, Annapolis, MD. General Technical Report NE-337, U.S. Dep. Agric. Forest Service, Northeastern Research Station, Newton Square, PA.

(NRCan) Natural Resources Canada. 2012. Emerald ash borer. (http:// cfs.nrcan.gc.ca/pages/318\#cn-nav).

Peng, F., S. Gardescu, and A. E. Hajek. 2011. Transmission of Metarhizium brunneum conidia between male and female Anoplophora glabripennis adults. BioControl 56: 771-780.

Rutledge, C. E., and M. A. Keena. 2012. Mating frequency and fecundity in the emerald ash borer Agrilus planipennis (Coleoptera: Buprestidae). Ann. Entomol. Soc. Am. 105: $66-72$.

Sabbahi, R., R. Lavallée, A. Merzouki, and C. Guertin. 2009. Differentiation of entomopathogenic fungus Beauveria bassiana (Ascomycetes: Hyprocreales) isolates by PCRRFLP. Phytoprotection 90: 49-56.

Sweeney, J., P. de Groot, L. MacDonald, S. Smith, S., C. Cocquempot, M. Kenis, and J. M. Gutowski. 2004. Host volatile attractants and traps for detection of Tetropium fuscum (F.), Tetropium castaneum L. and other longhorned beetles (Coleoptera: Cerambycidae). Environ. Entomol. 33: 844-854.

Systat Software, Inc. 2008. SigmaPlot for Windows version 11.0. Systat Software, Inc., Chicago, IL.

(USDA-APHIS) United States Department of Agriculture, Animal and Plant Health Inspection Service. 2011. U.S. Dep. Agric.-APHIS-PPQ-EAB trapping protocol, 2011 emerald ash borer survey. (http://www.aphis.usda.gov/ plant_health/plant_pest_info/emerald_ash_b/downloads/ trapping-protocols2011.pdf).

Vega, F. E., P. F. Dowd, and R. J. Bartelt. 1995. Dissemination of microbial agents using an autoinoculating device and several insect species as vectors. Biol. Control 5: $545-542$.

Wang, X.-Y., Z.-Q. Yang, J. R. Gould, Y.-N. Zhang, G.-J. Liu, and E.-S. Liu. 2010. The biology and ecology of the emerald ash borer, Agrilus planipennis, in China. J. Insect Sci. 10: 23 .

Wei, X., Y. Wu, R. Reardon, T.-H. Sun, M. Lu, and J.-H. Sun. 2007. Biology and damage traits of emerald ash borer (Agrilus planipennis Fairmaire) in China. Insect Sci. 14: 367-373.

Received 10 August 2012; accepted 7 September 2012. 